\title{
China-U.S. workshop on biotechnology of bioenergy plants
}

\author{
C. Neal Stewart Jr • Lee Shugart • Gong-She Liu • \\ Jie Zhuang $\cdot$ Yongqing Ma $\cdot$ Gerald A. Tuskan • \\ Richard Meilan - Randall W. Gentry - Gary S. Sayler
}

Published online: 5 December 2009

(C) Springer Science+Business Media, LLC 2009

The China and U.S. economies are the globally dominant drivers of fossil fuel consumption and release of greenhouse gases and are thus strategically linked to the sustainable development of sustainable, alternative, and renewable energy sources. Because of the dynamics and spatial interdependence between human activities and natural ecosystems, a major challenge arises: how to operate a renewable-energy economy within the ecological constraints of the biosphere. Renewable energy utilizes bio-based energy technology and other renewable sources as a substitute for fossil fuels. Although current levels and types of pollution associated with our present energy uses will decline, renewable energy technologies will introduce new environmental challenges that at present are only partly understood or defined. Therefore, a strategy is needed to address the uncertainty of these new activities, while attempting to protect natural ecological processes in order to sustain biological resources. Thus, we presume that the

C. N. Stewart Jr $(\bowtie)$

Department of Plant Sciences, The University of Tennessee, Knoxville, TN 37966, USA

e-mail: nealstewart@utk.edu

C. N. Stewart Jr · G. A. Tuskan · G. S. Sayler

BioEnergy Science Center, Oak Ridge, TN 37830, USA

L. Shugart

LR Shugart \& Associates, Inc., Oak Ridge, TN 37831-5564, USA

\section{G.-S. Liu}

Institute of Botany, Chinese Academy of Sciences, Beijing, China

J. Zhuang · R. W. Gentry

Institute for a Secure \& Sustainable Environment,

The University of Tennessee, Knoxville, TN 37996, USA combination of more intensive growth of agriculture and the production of bioenergy plants coupled with more sustainable management practices is an end goal worthy of scientific pursuit. The biotechnology of bioenergy plants will be an important component of this strategy as faster plant growth, pest resistance, and many other plant characteristics that will be required to meet these goals, many of which cannot be achieved in a reasonable time frame via conventional breeding.

China and the U.S. are natural partners for the development of biofuel technologies. Although there are differences in some aspects of their agriculture, natural resources, economy, and society, the two nations share many interests with respect to the environment, climate change, and scientific pursuits. In both the U.S. and China, it is hoped that the emerging bioenergy industry will give rise to a robust new rural economy in which ethanol and other biofuel and bioproduct production will meet

Y. Ma

Institute of Soil \& Water Conservation, Chinese Academy of Science, 712100 Yangling, Shaanxi, China

\section{G. A. Tuskan}

Environmental Sciences Division,

Oak Ridge National Laboratory, Oak Ridge,

TN 37830, USA

\section{R. Meilan}

Department of Forestry \& Natural Resources and the Center for the Environment, Purdue University, West Lafayette, IN 47907-2061, USA

\section{G. S. Sayler}

Center for Environmental Biotechnology,

Department of Microbiology, The University of Tennessee, Knoxville, TN 37996, USA 
mandates by expanding and diversifying to non-food, cellulosic feedstocks to meet current and future demand. The U.S. Department of Energy has completed the "BillionTon Study" describing how cellulosic feedstocks derived from our forests and dedicated bioenergy crops, such as switchgrass and poplar, are needed in order to achieve transportation biofuel goals over the next two decades (Perlack et al. 2005). In China, the government and renewable energy industry are poised to capitalize on the marketing potential of biofuels. China reports that a comparable billion tons of cellulosic material may be available annually for biofuel produced from agricultural wastes (NDRC 2007; Wang and Li 2007). China's twenty-first Century Agenda emphasizes renewable energy as a foundation for development in its Medium and Long-term Development Plan for Renewable Energy, which targets 30 GW of biomass power based on agricultural and forestry wastes and energy plants by 2020 (NDRC 2007).

Biomass production is facing many grand challenges in view of limits of available natural resources, such as land and water. Large-scale production of bioenergy will require a diverse suite of plants that tolerate environmental stresses in land not used for food and fiber crops and whose biomass is easy to convert to biofuels and bioproducts. In this regard, biotechnology offers huge potential for making breakthroughs in the near future. The use of biotechnology to improve bioenergy plants is currently developing very rapidly in the U.S. and China. For instance, The University of Tennessee, through its Biofuels Initiative (http://www. utbioenergy.org/TNBiofuelsInitiative), key industrial technology providers, and the BioEnergy Science Center (http://bioenergycenter.org), are developing and demonstrating the potential of cellulosic biomass (switchgrass and poplar) as a feedstock for ethanol production. Researchers at Purdue University are modifying lignin composition in poplar in an attempt to improve its utility as a bioenergy feedstock. In northwestern China, research on droughttolerant switchgrass is ongoing, while in east China many new species of energy plants, such as sorghum, are being studied and considered for industrial conversion to bioenergy.

To create opportunities for key Chinese and U.S. researchers to develop relationships and discuss the potential for scientific exchange, collaboration, and joint student education in this emerging bioenergy arena, the China-U.S. Joint Research Center for Ecosystem and Environmental Change co-sponsored a topical workshop on "Biotechnology of Bioenergy Plants" that was held in Knoxville, Tennessee, USA, on November 16-17, 2009. Specifically, the goals of the workshop were to: a) review the current advances in biological research on bioenergy plants, b) discuss future research directions of relevant bioenergy technologies, and c) identify joint research/ education programs in plant biotechnology that need to be developed between China and the U.S. Pertinent organizational information (i.e., agenda, participants, etc.) for this topical workshop can be found on the Joint Research Center's website (http://isse.utk.edu/jrceec).

Approximately 35 oral and poster presentations ranging from a marriage between the photosynthetic apparatus and material science to produce novel solar energy sources, to very applied aspects of switchgrass agronomy. Most presentations focused on the ligno-cellulosic feedstocks that are targets of the BioEnergy Science Center: poplar (Populus spp.) and switchgrass (Panicum virgatum) (Miller and Keller 2009). Poplar genomics and biotechnology flows from advanced tools including the availability of a sequenced genome (Tuskan et al. 2006). Association genetics and genomics are poised to be powerful technologies for further advancement of germplasm characteristics tailored for specific traits, such as cell-wall composition. As an example, data were presented on the effects of altering lignin composition in transgenic poplars by up- and down-regulating strategic genes in the lignin biosynthetic pathway.

Switchgrass has emerged as a promising herbaceous perennial feedstock because of its very wide adaptability, high biomass yield, and newly improved biotechnology methodologies (e.g., Burris et al. 2009). Of special interest was work described in growing switchgrass on the Loess Plateau in Shaanxi Province and Ningxia Autonomous Region in northwestern of China. The Loess Plateau contains highly degraded soil in a semi-arid environment (300-400 mm annual rainfall), where a 20,000 nondomesticated plant species selection test were performed and found the best growing plant was switchgrass (Ichizen et al. 1993, 2005). These efforts to establish switchgrass cultivation there has provided a new source of forage for cattle and sheep. Perhaps switchgrass would be an appropriate choice of feedstock for China too.

It was recognized that no single plant species will serve all bioenergy feedstock needs, but that diversity of adaptation will affect which plants are chosen for region and application (Wright 1994; Yuan et al. 2008). The group identified several projects worthy of joint research, in which mutual interest and synergies were clearly evident. These studies include the molecular analysis of switchgrass variability on the stress-selected accessions on the Loess Plateau, and analysis of cell-wall constituents. In northern China, Yang grass (Leymus chinensis) is one of the most important grasses, and is adapted to cool, dry habitats. Abiotic stress tolerance genes and wounding-induced genes from this grass discovered from GS-FLX (454) next-generation sequencing might be transferred to both woody and herbaceous bioenergy plants using genetic engineering techniques. In southern China, a woody energy plant, Jatropha curcas, was collected for evaluation for biodiesel production. However, seed production and cold resistance 
could limit widespread use of this woody energy plant in much of the China and U.S. Several other projects were discussed. These included the development of terpenebased fuels to novel plant oils whose chemical properties are being characterized, as well as their emissions during engine tests. Therefore, the Center envisages multidisciplinary approaches to address bioenergy problems that will be mutually beneficial to both the U.S. and China, and performed in cooperative efforts.

At this time, there are few funds earmarked for such joint bilateral projects, and therefore, regular research grants from each country can be (and have been) leveraged by collaborators with funds from U.S. institutions and the Chinese Academy of Science. Nonetheless, it appears that U.S. funding agencies such as NSF and USDA-NIFA could well increase targeted funds for such international cooperation. From the U.S. perspective, the combination of a China's burgeoning economy and scientific capacity is unequaled as a partner. From the Chinese perspective, respected U.S. universities and mature science culture could be helpful for training young scientists. To that end, post-doc exchanges are currently underway and student exchanges are being seriously discussed, and should be underway in 2010. These personnel exchanges follow plant germplasm transfers that have resulted in successful establishments and are spurring scientific synergies.

The enthusiastic support of the November 2009 workshop (approximately 50 attendees), including registrants from industry, led to calls for annual workshops to discuss bioenergy, plant genomics, biotechnology, and bioprocessing. The next meeting is tentatively planned to take place in Beijing, China, in the summer of 2010. Pre- or post-conference field trips to $\mathrm{Xi}$ ' An, to tour a switchgrass site on the Loess Plateau of northwest China and to Xishuangbanna for tropical forest site in southwestern China, will also be arranged. We believe the structure of a joint center among closely allied institutions between these key countries foreshadows the structure of collaborative research in the twenty-first century, since it optimizes exchanges of materials, scientists, and scientific discoveries in socially and culturally enriching context that is economically favorable.
Indeed, such efforts will certainly be required if we are to meet the very challenging environmental and energy problems that are facing the U.S., China, and the rest of the world.

Acknowledgments We wish to thank the following entities for funding the workshop: Chinese Academy of Science, Joint Institute for Biological Sciences, Southeastern Sun Grant Center, University of Tennessee AgResearch, Institute for a Secure and Sustainable Environment, and Office of Bioenergy Programs. Thanks also are due to Sherry Redus for the logistical organization of the workshop and Michelle Hassler for editorial assistance.

\section{References}

Burris JN, Mann DGJ, Joyce BL, Stewart CN Jr (2009) An improved tissue culture system for embyrogenic callus production and plant regeneration in switchgrass (Panicum virgatum L.). BioEnergy Res 2:267-274

Ichizen N, Ogasawara M, Kuramochi H, Konnai M, Sunohara W, Takemasu T (1993) Screening of weeds for vegetation recovery in a pasture in the semi-arid region of the Loess Plateau in China. Weed Res Japan 38:182-189 (in Japanese with English abstract)

Ichizen N, Takahashi H, Nishio T, Liu GB, Li DQ, Huang J (2005) Impacts of switchgrass (Panicum virgatum L.) planting on soil erosion in the hills of the Loess Plateau in China. Weed Biol Manag 5:31-34

Miller R, Keller M (2009) The DOE BioEnergy Science Center-a U.S. Department of Energy BioEnergy Research Center. In Vitro Cell Dev Biol-Plant 45:193-198

National Development and Reform Commission (NDRC), People's Republic of China (2007) Medium and long-term development plan for renewable energy in China

Perlack RD, Wright LL, Turhollow AF, Graham RL, Stokes BJ, and Erbach DC (2005) Biomass as feedstock for a bioenergy and bioproducts industry: the technical feasibility of a billion-ton annual supply, DOE/GO-102005-2135, Oak Ridge National Laboratory, Oak Ridge, TN. http://feedstockreview.ornl.gov/pdf/ billion_ton_vision.pdf

Tuskan GA et al (2006) The genome of black cottonwood, Populus trichocarpa. Science 313:1596-1604

Wang Z, Li J (2007) Report of renewable energy industry of China (Chinese). Chemical Industrial Press, Beijing

Wright LL (1994) Production technology status of woody and herbaceous crops. Biomass Bioenergy 6:191-209

Yuan JS, Tiller KH, Al-Ahmad H, Stewart NR, Stewart CN Jr (2008) Plants to power: bioenergy to fuel the future. Trends Plant Sci $13: 421-429$ 